\title{
Distribution of Oligomannosyl Side Chains in the Cell Wall Mannan of Pichia pastoris Purified by Benanomicin A
}

\author{
Takuya Kuraoka ${ }^{1}$, Momoka Shukuri ${ }^{1}$, Saki Iwanaga ${ }^{1}$, Takayoshi Yamada ${ }^{2}$, \\ Yukiko Ogawa ${ }^{1}$ and Hidemitsu Kobayashi ${ }^{1 *}$
}
${ }^{1}$ Laboratory of Microbiology, Department of Pharmacy, Faculty of Pharmaceutical Science, Nagasaki International University, 2825-7 Huis Ten Bosch, Sasebo, Nagasaki 859-3298, Japan
${ }^{2}$ Sanko Medical Tomato Pharmacy Co., Ltd., 2023-2, Shimogumigo, Higashisonogigun, Kawatanacho, Nagasaki, 859-3615, Japan

*Corresponding author

\section{A B S T R A C T}

In the previous study, a new method was established to prepare mannan under mild conditions by using antibiotic Benanomicin A. In this study, this method was applied to the isolation of $P$. pastoris NBRC 0984 mannan which predominantly contains $\beta-1,2-$ linked mannose residues. As the findings of nuclear magnetic resonance (NMR) analysis of the resultant mannan to examine the distribution state of the side chain, it was found that despite the existence of oligomannosyl side chains corresponding to pentaose, Man $\alpha 1 \rightarrow 2$ Man $\beta 1 \rightarrow$ Man $\beta 1 \rightarrow$ Man $\alpha 1 \rightarrow 2$ Man, tetraose, Man $\beta 1 \rightarrow$ Man $\beta 1 \rightarrow$ Man $\alpha 1 \rightarrow 2$ Man, and biose, Man $\alpha 1 \rightarrow 2 \mathrm{Man}$, in this molecule, the side chain corresponding to triose, Man $\beta 1 \rightarrow$ Man $\alpha 1 \rightarrow 2$ Man, was not detected at all. In our previous study, a relatively large number of biosyl and triosyl side chains were detected in analyzes applying acetolysis to mannans prepared by the Fehling method from the same yeast cells. Such a difference can be explained as that the $\beta-1,2$-linkages of some pentaosyl and tetraosyl side chains were cleaved by acetolysis, and triose and biose occurred secondarily in large quantities. In conclusion, the best way to accurately measure the side chain distribution of mannan is to perform NMR analysis on untreated mannan molecules prepared under mild conditions using Benanomicin A.

\section{Introduction}

In carbohydrate biochemistry, acetolysis is the one of the important procedures for the selective cleavage of $\alpha$-1,6-linkages. This method was frequently used for the structural and immunochemical studies of various yeast mannans (Kocourek et al., 1969; Shibata et $a l ., 2012$ ), and for the preparation of several substrates for transferases in biosynthetic studies of yeast mannan (Suzuki et al., 1996; Shibata and Okawa, 2010). Gorin and Perlin (Gorin and Perlin, 1956) first applied acetolysis to the structural study of yeast mannans, and were succeed to isolate Man $\alpha 1 \rightarrow 2$ Man. Thereafter, many reports 
were published utilizing acetolysis to structural study of various yeast mannans (Kocourek et al., 1969; Suzuki and Sunayama, 1968 a, b; Gorin et al., 1969; Hamada et al., 1981; Funayama et al., 1984). At about the same time, Gorin and Spencer (Gorin and Spencer, 1970) indicates that some yeast mannans contain $\beta$-linked mannose residues from the results of NMR studies. After a while, Kobayashi et al. (Kobayashi et al., 1986, 1988) developed mild acetolysis that be able to isolate mannooligosaccharides containing $\alpha-1,2-$ and $\beta-1,2-$ linkages from the mannan of Pichia pastoris. After that, this method was widely used the analysis for chemical structure of cell wall mannan of pathogenic yeast, genus Candida (Kobayashi et al., 1987, 1989, 1992 a). At the same time as these studies, NMR development and dissemination were achieved, and this technical application enabled more detailed analysis of mannan sugar chains (Kobayashi et al., 1990; Shibata et al., 1993 a).

In carrying out structural analysis of yeast mannan, one of most important point is separating and refining of intact mannan molecule. What used to isolate yeast cell wall mannan so far is a method of precipitating mannan as a copper complex using a Fehling reagent. However, since this preparation method has a step of immersing in a strongly alkaline solution, there is a possibility that the resultant mannan has been damaged. Therefore, in the previous study (Kuraoka et al., 2018), we developed a new mannan preparation method using Benanomicin A which is an antibiotic having lectin-like activity. In this way, the mannan composed only of $\alpha$-linked mannose residues could be prepared successfully from pathogenic yeast Candida krusei (Kuraoka et al., 2018).

In the present study, we demonstrate the usefulness of new purification method of yeast cell wall mannan using Benanomicin A.
Namely, we adopted a new method for the preparation of intact mannan containing a large number of $\beta$-1,2-linkage from $P$. pastoris NBRC 0984 (formerly IFO 0984). Then, this mannan was analyzed by NMR, twodimensional isotope Hartmann-Hearn (2DHOHAHA) and ${ }^{13} \mathrm{C}-{ }^{1} \mathrm{H}$ correlation spectroscopy (C-H COSY) to ascertain the exact distribution of oligomannosyl side chains.

\section{Materials and Methods}

\section{General}

Pichia pastoris NBRC 0948 (formerly IFO 0948) strain were obtained from the Biological Resource Center (NBRC), National Institute of Technology and Evaluation (NITE), Japan. The cells were cultivated in the yeast extractSabouraud's liquid medium $[0.5 \%(\mathrm{w} / \mathrm{v})$ yeast extract, $1 \%(\mathrm{w} / \mathrm{v})$ peptone, and $2 \%(\mathrm{w} / \mathrm{v})$ glucose] at $27^{\circ} \mathrm{C}$ for 72 hours on a reciprocal shaker.

Benanomicin A was kindly provided by Dr. Shuichi Gomi (Pharmaceutical Research Center, Meiji Seika Kaisha, Ltd.).

\section{Preparation of crude extract from Pichia pastoris NBRC 0948}

This was prepared according to the previous report (Kuraoka et al., 2018). Yield of crude extract was $13.2 \%$ based on an acetone-dried cells weight.

Preparation of cell wall mannans of $\boldsymbol{P}$. pastoris by two different procedures

Preparation of mannan using Benanomicin A was performed according to previously described (Kuraoka et al., 2018). This method is referred to as a Benanomicin method. Purified mannan by this method is abbreviated as Fr. P-B. On the other hand, mannan was 
prepared using Fehling reagent as previously described (Okubo et al., 1978). Fehling reagent consists of a $1: 1(\mathrm{v} / \mathrm{v})$ mixture of $3.5 \%$ $\mathrm{CuSO}_{4} 5 \mathrm{H}_{2} \mathrm{O}, 17.3 \%$ Rochelle salt and $5.0 \%$ $\mathrm{NaOH}$. This method is referred to as the Fehling method. Purified mannan by this method is abbreviated as Fr. P-F.

\section{NMR analysis of mannans}

${ }^{1} \mathrm{H}-\mathrm{NMR}$ spectra (internal acetone, $2.217 \mathrm{ppm}$ ) were measured with a Jeol JNM-GSX 400 spectrometer on solutions (3-10mg sample/0.7mL) in $\mathrm{D}_{2} \mathrm{O}$ at $70^{\circ} \mathrm{C} .{ }^{13} \mathrm{C}-\mathrm{NMR}$ spectra (internal $\mathrm{CD}_{3} \mathrm{OD}, 49.00 \mathrm{ppm}$ ) were measured with the same spectrometer on solutions $\left(15-25 \mathrm{mg}\right.$ sample/0.7mL) in $\mathrm{D}_{2} \mathrm{O}$ at $55^{\circ} \mathrm{C}$. 2D-HOHAHA spectrum was recorded for a solution $(10 \mathrm{mg}$ sample/ $/ 0.7 \mathrm{~mL})$ in $\mathrm{D}_{2} \mathrm{O}$ at $45^{\circ} \mathrm{C} .{ }^{13} \mathrm{C}-{ }^{1} \mathrm{H}$ COSY spectra were also recorded under the same conditions as for the ${ }^{1} \mathrm{H}$ and ${ }^{13} \mathrm{C}$ NMR spectra. The percentage of the different kinds of oligomannosyl side chains in mannan was calculated based on the peak-dimensions of the corresponding $\mathrm{H}-1$ signals in the ${ }^{1} \mathrm{H}-\mathrm{NMR}$ spectrum (Kobayashi et al., 1997).

\section{Calculation of average length of side chains}

The average length of side chains $(X)$ of calculated by using the following formula in accordance with previous descriptions (Kobayashi et al., 2003):

$X=[(\mathrm{A} \times 1)+(\mathrm{B} \times 2)+(\mathrm{C} \times 3)+(\mathrm{D} \times 4)+$ $(\mathrm{E} \times 5)] /(\mathrm{A}+\mathrm{B}+\mathrm{C}+\mathrm{D}+\mathrm{E})$,

Where A through E represent the molar proportions of mannose, biose, triose, tetraose, and pentaose in the peak-dimensions of the corresponding $\mathrm{H}-1$ signals in the ${ }^{1} \mathrm{H}-\mathrm{NMR}$ spectrum, and the numbers 1 through 5 indicate the degrees of polymerization of the mannose $\left(\mathrm{M}_{1}\right)$ and the four oligosaccharides, $\mathrm{M}_{2}$ through $\mathrm{M}_{5}$, respectively.

\section{Results and Discussion}

${ }^{1}$ H-NMR analysis of mannans, Fr. P-B and P-F

The chemical structure of mannan was analyzed by means of ${ }^{1} \mathrm{H}-\mathrm{NMR}$ (Figure 1 ). The spectra of both fractions showed extremely similar patterns in the anomeric proton region (range of 4.7 to $5.7 \mathrm{ppm}$ ). This finding supports the new purification method of yeast mannan being as effective as conventional methods. Therefore, it is cleared that Benanomicin method was successfully prepared even mannan having a large amount of $\beta$-linkage. The absence of any signal in the range of 5.40 to $5.70 \mathrm{ppm}$ indicates that both fractions do not contain mannose residues via a phosphodiester bond. Three strong signals derived from $\alpha$-1,2- and $\alpha$-1,6-linked mannose residues $(5.100,5.071$ and $4.876 \mathrm{ppm})$, and four strong signal derived from $\alpha-1,2$ and $\beta$ 1,2-linked mannose residue $(5.376,5.159$, 4.844 and $4.834 \mathrm{ppm}$ ) were observed in the pattern of both fractions. In summary, as a result of assignment of each signal based on our previous report (Gorin et al., 1969), it became clear that cell wall mannan contains $\alpha$ 1,2-, $\alpha-1,6-$ and $\beta-1,2-$ linked mannose residue. These results are consistent with previous report (Kobayashi et al., 1986). Therefore, we conducted following experiments using Fr. PB.

\section{Two-dimensional NMR analysis of Fr. P-B}

Verification of overall structure of Fr. P-B was attempted by chemical shift values of crosspeaks on two kinds of two-dimensional NMR maps. Figure 2 shows the two-dimensional map of 2D-HOHAHA spectrum of Fr. P-B. Nine cross-peaks, identified based on previous reports (Shibata et al., 1993 a, 1996), were observed. Namely, the appearance of crosspeaks 1, 2 and 3 indicates that mannan contain $\beta$-1,2-linked oligomannosyl side chains. 
Cross-peaks 6,7 or 4 correspond to the 2-Osubstituted or unsubstituted forms of the $\alpha$ 1,6-linked polymannosyl backbone, respectively. On the other hand, the presence of $\alpha$-1,2-linked mannose residues was demonstrated by the appearance of crosspeaks 5 and 8. Cross-peak 9 indicates the existence of $\alpha$-1,2-linked mannose residues in the non-reducing terminal of long side chain. Figure 3 shows the two-dimensional map of ${ }^{13} \mathrm{C}-{ }^{1} \mathrm{H}$ COSY spectrum of Fr. P-B. Eleven cross-peaks, identified based on previous reports (Shibata et al., 1993 b), were observed. The presence of cross-peak C, D, I and $\mathrm{J}$ indicates that mannan contain $\beta$-1,2-linked oligomannosyl side chains. Cross-peaks A, B or $\mathrm{E}$ correspond to the 2-O-substituted or unsubstituted forms of the backbone in which $\alpha$-1,2-linked mannose residues are polymerized, respectively. The existence of $\alpha$ 1,2-linked mannose residues was confirmed by the appearance of cross-peaks $\mathrm{F}, \mathrm{H}$ and $\mathrm{K}$. Cross-peak $\mathrm{G}$ indicates the existence of $\alpha-1,2-$ linked mannose residues in the non-reducing terminal of long side chain. Therefore, the chemical shifts in the spectra of Fr. P-B were assigned according to published data (Shibata et al., 1993 b, 2010; Kobayashi et al., 1991, 1992 b, 1998; Shibata et al., 2007; Oyamada et al., 2008), as in Table 1. It is cleared that this mannan has oligomannosyl side chain corresponding to biose (Man $\alpha 1 \rightarrow 2$ Man), tetraose

$(\mathrm{Man} \beta 1 \rightarrow 2 \mathrm{Man} \beta 1 \rightarrow 2 \mathrm{Man} \alpha 1 \rightarrow 2 \mathrm{Man}) \quad$ and pentaose

$(\mathrm{Man} \alpha 1 \rightarrow 2 \mathrm{Man} \beta 1 \rightarrow 2 \mathrm{Man} \beta 1 \rightarrow 2 \mathrm{Man} \alpha 1 \rightarrow 2 \mathrm{M}$ an).

\section{Overall structure of Fr. P-B}

As shown in Figure 4, the distribution of the side chains in Fr. P-B was calculated based on the dimensions of the characteristic $\mathrm{H} 1$ signals of the side chains labeled with asterisks in Table 1. The distribution of side chains of $P$. pastoris mannans which were analyzed by two kinds of procedures was clearly different. Particularly remarkable is that NMR analysis of Fr. P-B did not detect a triosyl side chain (Figure 4A). In the previous paper (Kobayashi et al., 1986), the triose, $\operatorname{Man} \beta 1 \rightarrow$ Man $\alpha 1 \rightarrow 2$ Man, as acetolysate has been obtained from mannan prepared by Fehling method (Figure 4B: the part surrounded by the dotted line). In addition, the distribution of side chains of Fr. P-B was calculated from the dimensions of anomeric proton (H-1) signals in the NMR spectrum.

Figure. $1{ }^{1} \mathrm{H}-\mathrm{NMR}$ spectra (anomeric region) of $P$. pastoris mannan, Frs. P-B (A) and P-F (B)

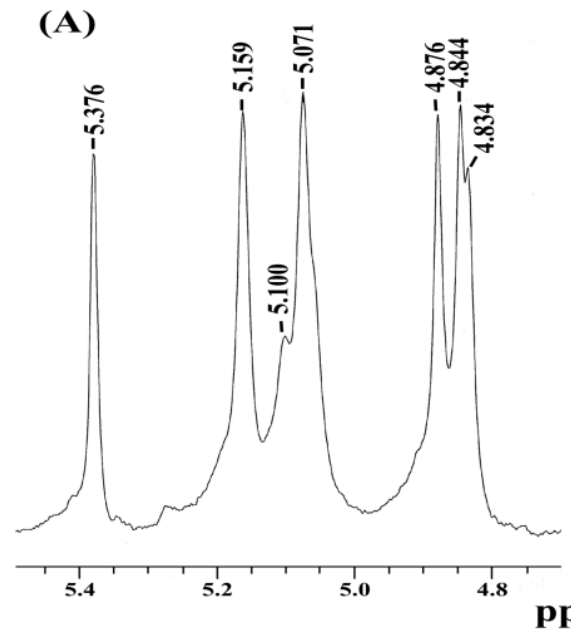

(B)

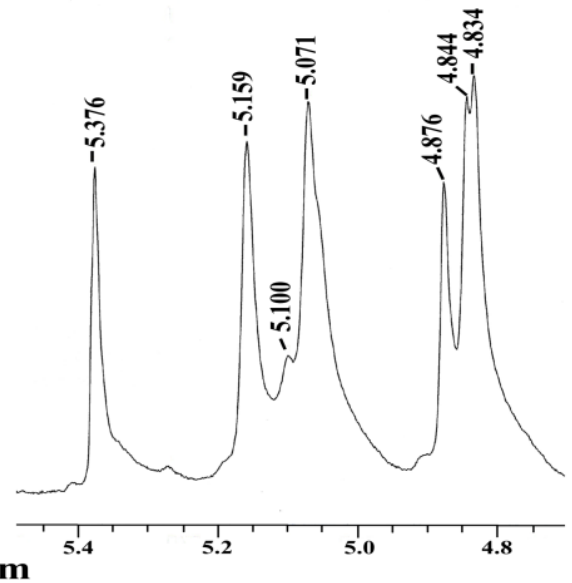


Table.1 Assignment of ${ }^{1} \mathrm{H}$ and ${ }^{13} \mathrm{C}$ NMR chemical shifts of Fr. P-B. Man indicate mannose residue. Side chain sequence is not specified. Asterisks indicate characteristic H1 signal of each side chain

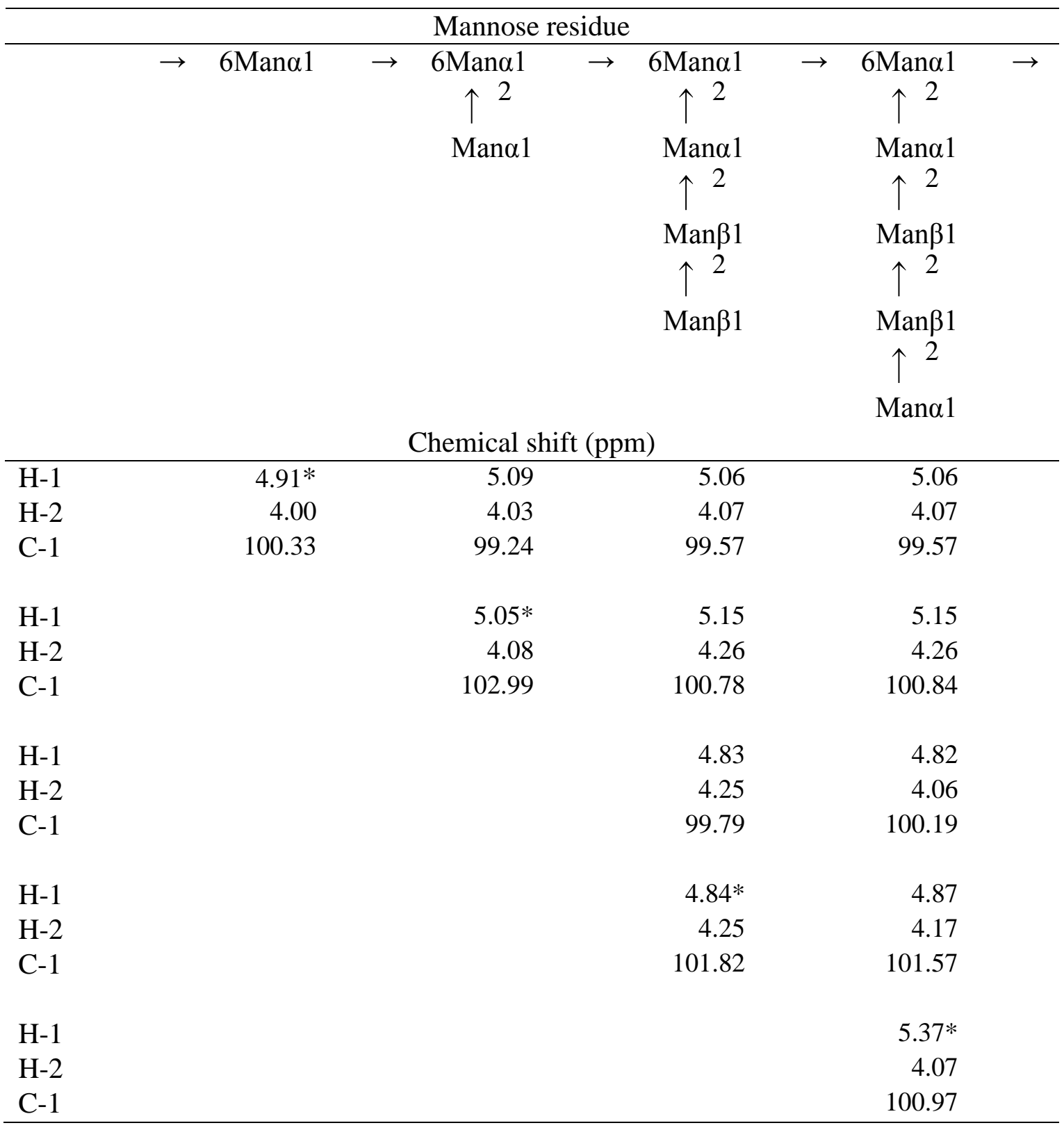


Figure.2 2D-HOHAHA spectrum of Fr. P-B. Boxed cross-peaks are H-1 and H-2 correlated by J-coupling

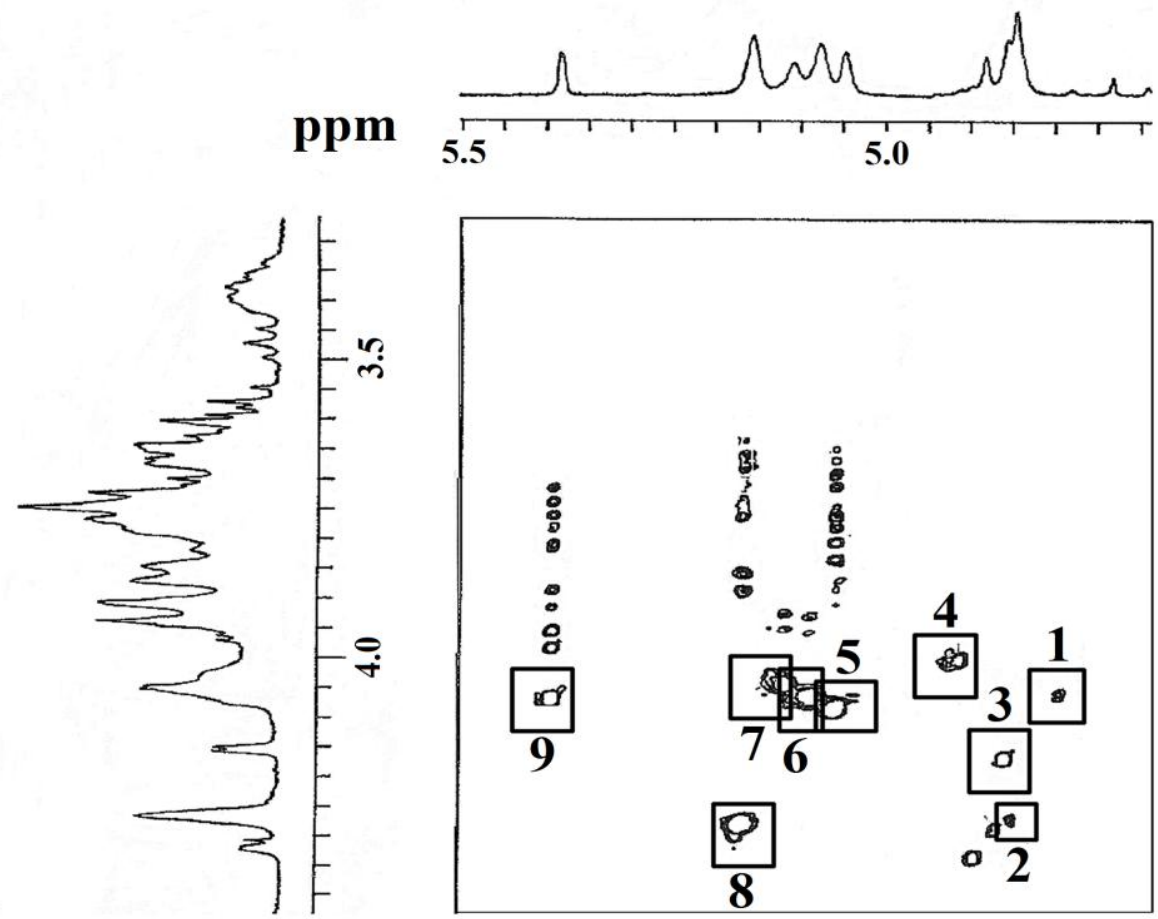

\section{H 1}

H 2

Figure. ${ }^{13} \mathrm{C}-{ }^{1} \mathrm{H}$ COSY spectrum of Fr. P-B. Boxed cross-peaks are $\mathrm{H}-1$ and $\mathrm{C}-1$ correlated by J-coupling

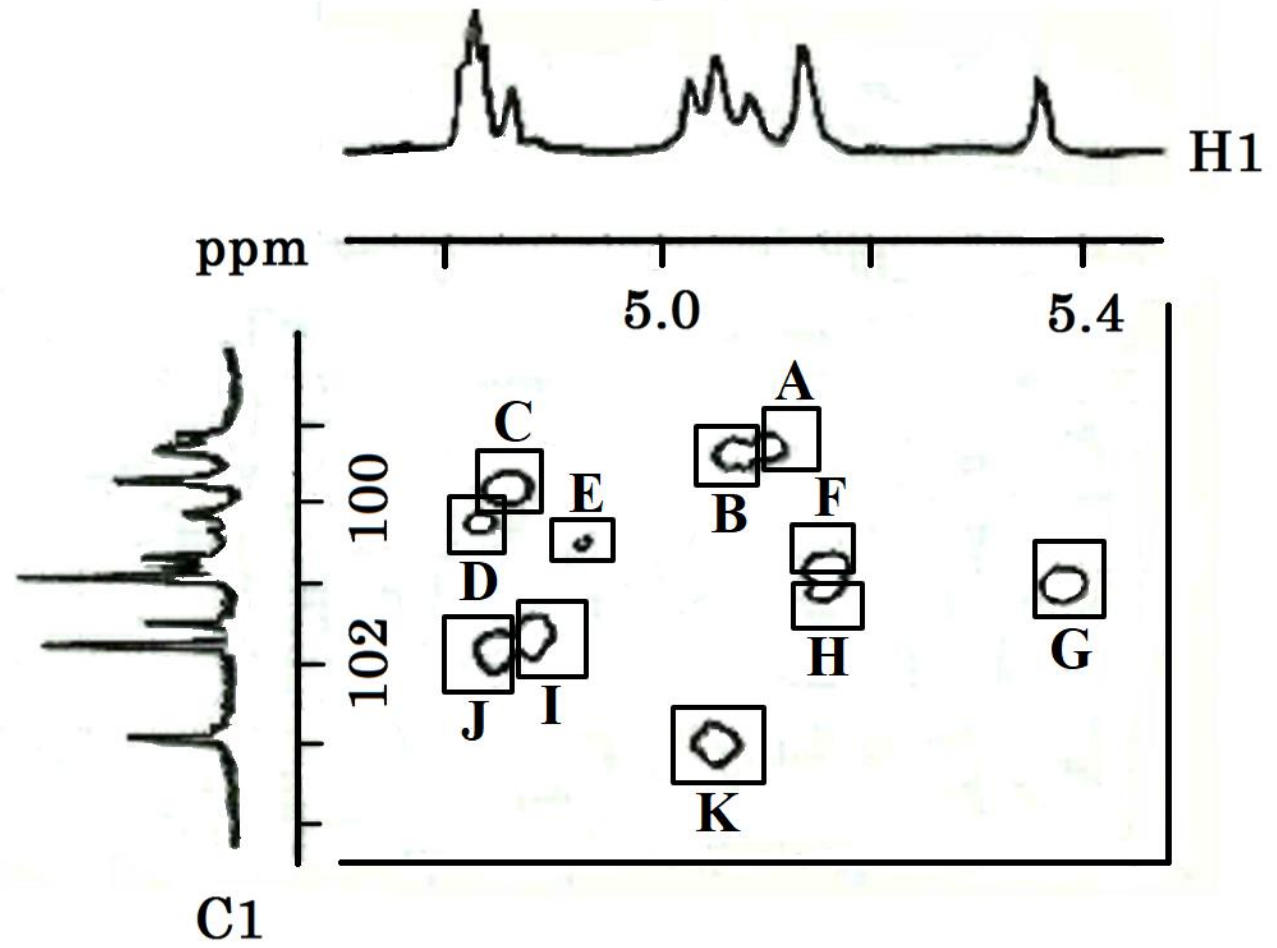


Figure.4 Structure of $P$. pastoris NRBC 0948 mannan. (A) Side chain distribution was calculated based on the dimensions of characteristic $\mathrm{H}-1$ signals of each side chain in the ${ }^{1} \mathrm{H}$ NMR spectroscopy map (Shibata et al., 1996). (B) Side chain distribution was calculated based on the peak-dimensions in the gel-filtration profile of the mild acetolysis products. $\mathrm{M}$ indicate mannose residue. *These values were referred from previous report (Kobayashi et al., 1988). Side chain sequence is not specified. The part surrounded by the dotted line is indicates that it was not detected by NMR

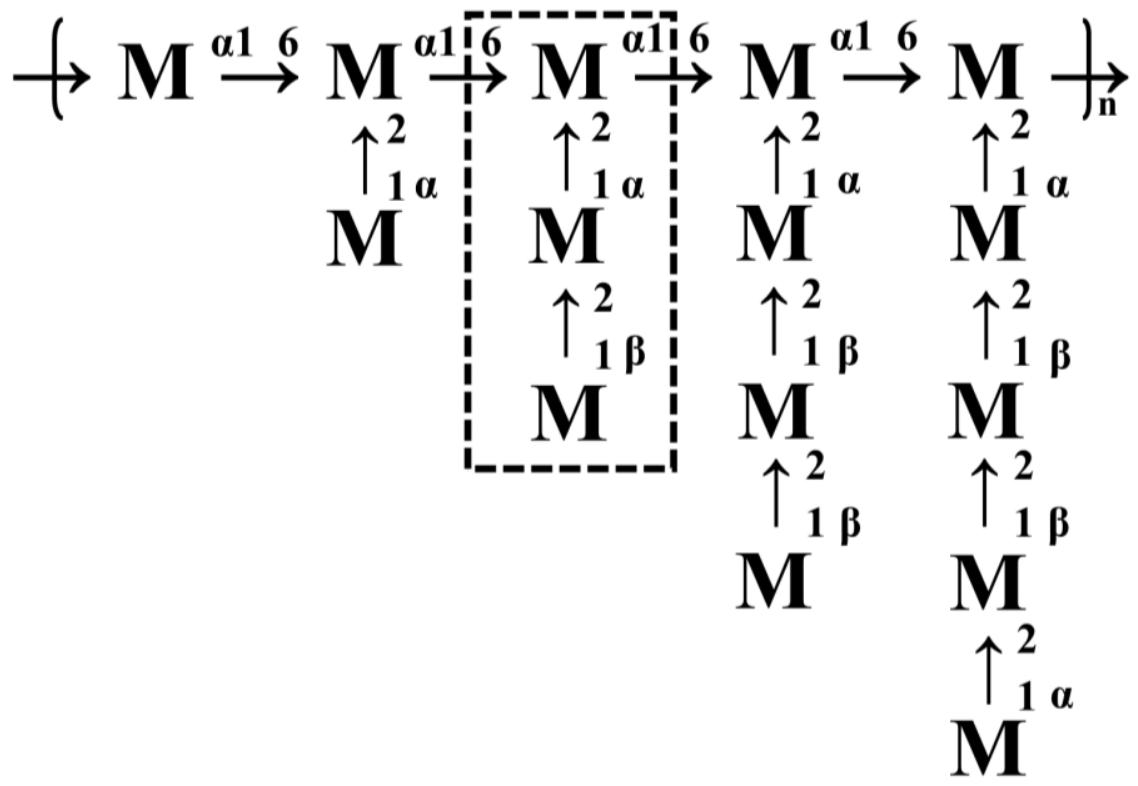

\section{Side chain distribution}

\begin{tabular}{|c|c|c|c|c|c|c|c|c|}
\hline (A) & 9.60 & & 26.36 & & - & : & 36.85 & : 27.19 \\
\hline В) & 4.64 & & 34.47 & & 4.06 & & 32.32 & \\
\hline
\end{tabular}

Total molar ratio of tetraosyl and pentaosyl side chains, 64.04 (Figure 4A), was higher than that of same oligonanosyl side chain calculated by elution profile of acetolysates in our previous description (Kobayashi et al., 1986), 46.83 (Figure 4B). Conversely, the total ratio of biosyl side chains and nonsubstituted backbone moieties of Fr. P-B, 35.96, was calculated to be much lower than the same ratio in our previous report (Kobayashi et al., 1986), 49.11. Comparing the average lengths of the side chains of two mannans analyzed by different procedures, it was 3.5 for Fr. P-B, whereas the mannan in the previous report (Kobayashi et al., 1986) was relatively short, 3.0.

In this study, we demonstrated that the new yeast mannan preparation method using Benanomicin A developed in our previous report (Kuraoka et al., 2018) is applicable not only to mannan composed of $\alpha$-linkage but also to preparation of mannan containing $\beta$ linkage. Therefore, it is of interest whether the antibiotic Benanomicin A can also be used for preparing heteropolysaccharides containing mannose residues. 
The fact that the distribution of side chains of $P$. pastoris mannans analyzed by the two procedures is clearly different suggests that a part of a slightly longer side chain of mannan is hydrolyzed in the process of acetolysis. This interpretation is also supported by the difference in the average chain length of both mannans. Additionally, no detection of the triosyl side chains in the $P$. pastoris mannan suggests that the $\beta$-1,2-mannosyltransferases work more quickly than $\alpha-1,2$ mannosyltransferases and contribute to the construction of tetraosyl and pentaosyl side chains in the biosynthetic process of mannan.

In conclusion, it is certain that polysaccharide resolution, such as acetolysis, is useful for preparing oligosaccharides corresponding to key fragments of various immunochemical or biological functions. However, as a tool for obtaining accurate information on the chemical structure of an intact polysaccharide, various applied NMR analyzes are optimal rather than restricted decomposition methods. Therefore, it was shown in this report, one of the most convenient structural analyzes of yeast mannan is a method using Benanomicin A and two-dimensional NMR.

\section{References}

Funayama, M., Nishikawa, A., Shinoda, T., Suzuki, M., Fukazawa, Y., 1984. Antigenic relationship between Candida parapsilosis and Candida albicans serotype B. Microbiol. Immunol. 28, 1359-1371.

Gorin, P.A.J., Perlin, A.S., 1956. A mannan produced by Saccharomyces rouxii. Canad. J. Chem. 34, 1796-1803.

Gorin, P.A.J., Spencer, J.F.T., 1970. Proton magnetic resonance spectroscopy-an aid in identification and chemotaxonomy of yeasts. Adv. Appl. Microbiol. 13, 25-89.
Gorin, P.A.J., Spencer, J.F.T., Bhattacharjee, S.S., 1969. Structures of yeast mannans containing both $\alpha$ - and $\beta$ linked D-mannopyranose units. Can. J. Chem. 47, 1499-1505.

Hamada, T., Nakajima, T., Izaki, K., Matsuda, K., 1981. Comparison of the mannan structure from the cell wall mutant Candida sp. M-7002 and its wild type. Eur. J. Biochem. 119, 365371.

Kobayashi H, Shibata N, Watanabe M, Komido M, Hashimoto, N., Hisamichi, K., Suzuki, S., 1992 b. Mild acetolysis and NMR studies of the D-mannan of Saccharomyces cerevisiae X2180-1A wild-type strain. Carbohydr. Res. 231, 317-323.

Kobayashi, H., Giummelly, P., Takahashi, S., Ishida, M., Sato, J., Takaku, M., Nishidate, Y., Shibata, N., Okawa, Y., Suzuki, S., 1991. Candida albicans serotype A strains grow in yeast extract-added Sabouraud liquid medium at $\mathrm{pH}$ 2.0, elaborating mannans without $\beta-1,2$ linkage and phosphate group. Biochem. Biophys. Res. Commun. 175, 1003-1009.

Kobayashi, H., Mitobe, H., Takahashi, K., Yamamoto, T., Shibata, N., Suzuki S., 1992 a. Structural study of a cell wall mannan-protein complex of the pathogenic yeast Candida glabrata IFO 0622 strain. Arch. Biochem. Biophys. 294, 662-9.

Kobayashi, H., Oyamada, H., Iwadate, N., Szuki, H., Mitobe, H., Takahashi, K., Shibata, N., Suzuki, S., Okawa, Y., 1998. Structural and immunochemical characterization of $\beta$-1,2-linked mannobiosyl phosphate residue in the cell wall mannan of Candida glabrata. Arch. Microbiol. 169, 188-194.

Kobayashi, H., Oyamada, H., Matsuda, K., Shibata, N., Suzuki, S., 2003. Distribution of antigenic 
oligomannosyl side chains in the cell wall mannans of several strains of Candida tropicalis. Arch. Microbiol. 180, 76-80.

Kobayashi, H., Shibata, N., Mitobe, H., Ohkubo, Y., Suzuki, S., 1989. Structural study of phosphomannan of yeast-form cells of Candida albicans J-1012 strain with special reference to application of mild acetolysis. Arch. Biochem. Biophys. 272, 364-375.

Kobayashi, H., Shibata, N., Nakada, M., Chaki, S., Mizugami, K., Ohkubo, Y., Suzuki, S., 1990. Structural study of cell wall phosphomannan of Candida albicans NIH B-792 (serotype B) strain, with special reference to ${ }^{1} \mathrm{H}$ and ${ }^{13} \mathrm{C}$ NMR analyses of acid-labile oligomannosyl residues. Arch. Biochem. Biophys. 278, 195-204.

Kobayashi, H., Shibata, N., Suzuki, S., 1986. Acetolysis of Pichia pastoris IFO 0948 strain mannan containing $\alpha-1,2$ and $\beta-1,2$ linkages using acetolysis medium of low sulfuric acid concentration. Arch. Biochem. Biophys. 245, 494-503.

Kobayashi, H., Shibata, N., Suzuki, S., 1987. Structural study of phosphomannanprotein complex of Citeromyces matriensis containing $\beta-1,2$ linkage. Application of partial acid degradation and acetolysis techniques under mild conditions. Arch. Biochem. Biophys. 256, 381-396.

Kobayashi, H., Shibata, N., Suzuki, S., 1988, Application of mild acetolysis to confirm the comb-like structure of cell wall mannan from Pichia pastoris IFO 0948 strain. Chem. Pharm. Bull. 36, 3168-3172.

Kobayashi, H., Suzuki, J., Tanaka, S., Kiuchi, Y., Oyamada, H., Iwadate, N., Suzuki, H., Shibata, N., Suzuki, S., Okawa, Y., 1997. Structure of a cell wall mannan from the pathogenic yeast, Candida catenulata: Assignment of ${ }^{1} \mathrm{H}$ nuclear magnetic resonance chemical shifts of the inner $\alpha$-1,6-linked mannose residues substituted by a side chain. Arch. Biochem. Biophys. 341, 70-74.

Kocourek, J., Ballou, C.E., 1969. Method for fingerprinting yeast cell wall mannans. J. Bacteriol. 100, 1175-1181.

Kuraoka, T., Ishiyama, A., Oyamada, H., Ogawa, Y., Kobayashi, H., 2018. Presence of O-glycosidically linkedoligosaccharides in the cell wall mannoprotein of Candida krusei purified with Benanomicin A. "in press"

Okubo, Y., Ichikawa, T., Suzuki, S., 1978. Relationship between phosphate content and immunochemical properties of subfractions of bakers' yeast mannan. J. Bacteriol. 136, 6368.

Oyamada, H., Ogawa, Y., Shibata, N., Okawa, Y., Suzuki, S., 2008. Structural analysis of cell wall mannan of Candida sojae, a new yeast species isolated from defatted soybean flakes. Arch. Microbiol. 189, 483-890.

Shibata, N., Akagi, R., Hosoya, T., Kawahara, K., Suzuki, A., Ikuta, K., Kobayashi, H., Hisamichi, K., Okawa, Y., Suzuki, S., 1996. Existence of novel branched side chains containing $\beta-1,2$ and $\alpha-1,6$ linkages corresponding to antigenic factor 9 in the mannan of Candida guilliermondii. J. Biol. Chem. 271, 9259-9266.

Shibata, N., Hisamichi, K., Kobayashi, H., Suzuki, S., 1993 b. Complete assignment of ${ }^{1} \mathrm{H}$ and ${ }^{13} \mathrm{C}$ nuclear magnetic resonance chemical shifts of $\beta$-1,2-linked mannooligosaccharides isolated from the phosphomannan of the pathogenic yeast Candida albicans NIH B-792 strain. Arch. Biochem. Biophys. 169, 188-94.

Shibata, N., Kobayashi, H., Suzuki, S., 2012. 
Immunochemistry of pathogenic yeast, Candida species, focusing on mannan. Proc. Jpn. Acad. Ser. B. Phys. Biol. Sci. 88, 250-265.

Shibata, N., Kojima, C., Satoh, Y., Satoh, R., Suzuki, A., Kobayashi, H., Suzuki, S., 1993 a. Structural study of a cell-wall mannan of Saccharomyces kluyveri IFO 1685 strain. Presence of a branched side chain and $\beta$-1,2-linkage. Eur. J. Biochem. 217, 1-12.

Shibata, N., Okawa, Y., 2010. Enzymatic synthesis of new oligosaccharides using mannosyltransferases from Candida species and their NMR assignments. Biol. Pharm. Bull. 33, 895-899.

Shibata, N., Suzuki, A., Kobayashi, H., Okawa, Y., 2007. Chemical structure of the cell-wall mannan of Candida albicans serotype A and its difference in yeast and hyphal forms. Biochem. J. 404, 365-372.

Suzuki A, Shibata N, Suzuki M, Saitoh F, Takata Y et al. (1996) Characterization of $\alpha-1,6-$ mannosyltransferase responsible for the synthesis of branched side chains in Candida albicans mannan. Eur $J$ Biochem 240: 37-44.

Suzuki, S., Sunayama, H., 1968 b. Studies on the antigenic activities of yeasts. II. Isolation and inhibition assay of the oligosaccharides from acetolysate of the mannan of Candida albicans. Jpn. J. Microbiol. 12, 413-422.

Suzuki, S., Sunayama, H., Saito, S., 1968 a. Studies on the antigenic activity of yeasts. I. Analysis of the determinant groups of the mannan of Saccharomyces cerevisiae. Jpn. J. Microbiol. 12, 19-24.

\section{How to cite this article:}

Takuya Kuraoka, Momoka Shukuri, Saki Iwanaga, Takayoshi Yamada, Yukiko Ogawa and Hidemitsu Kobayashi. 2019. Distribution of Oligomannosyl Side Chains in the Cell Wall Mannan of Pichia pastoris Purified by Benanomicin A. Int.J.Curr.Microbiol.App.Sci. 8(01): 2926-2935. doi: https://doi.org/10.20546/ijcmas.2019.801.311 